\title{
RAP1GAP inhibits cytoskeletal remodeling and motility in thyroid cancer cells
}

\author{
Xiaoyun Dong ${ }^{1}$, Waixing Tang ${ }^{2}$, Stephen Stopenski, Marcia S Brose ${ }^{2}$, \\ Christopher Korch ${ }^{3}$ and Judy L Meinkoth ${ }^{1}$
}

Departments of ${ }^{1}$ Pharmacology and ${ }^{2}$ Otorhinolaryngology - Head and Neck Surgery, School of Medicine, University of Pennsylvania, 421 Curie Boulevard, BRB II/III, Philadelphia, Pennsylvania 19104, USA

${ }^{3}$ UCCC DNA Sequencing and Analysis Core, University of Colorado Cancer Center, University of Colorado, Denver, Colorado, USA

(Correspondence should be addressed to J L Meinkoth; Email: meinkoth@upenn.edu)

\begin{abstract}
The functional significance of decreased RAP1GAP protein expression in human tumors is unclear. To identify targets of RAP1GAP downregulation in the thyroid gland, RAP1 and RAP2 protein expression in human thyroid cells and in primary thyroid tumors were analyzed. RAP1GAP and RAP2 were co-expressed in normal thyroid follicular cells. Intriguingly, RAP1 was not detected in normal thyroid cells, although it was detected in papillary thyroid carcinomas, which also expressed RAP2. Both RAP proteins were detected at the membrane in papillary thyroid tumors, suggesting that they are activated when RAP1GAP is downregulated. To explore the functional significance of RAP1GAP depletion, RAP1GAP was transiently expressed at the lowest level that is sufficient to block endogenous RAP2 activity in papillary and anaplastic thyroid carcinoma cell lines. RAP1GAP impaired the ability of cells to spread and migrate on collagen. Although RAP1GAP had no effect on protein tyrosine phosphorylation in growing cells, RAP1GAP impaired phosphorylation of focal adhesion kinase and paxillin at sites phosphorylated by SRC in cells acutely plated on collagen. SRC activity was increased in suspended cells, where it was inhibited by RAP1GAP. Inhibition of SRC kinase activity impaired cell spreading and motility. These findings identify SRC as a target of RAP1GAP depletion and suggest that the downregulation of RAP1GAP in thyroid tumors enhances SRC-dependent signals that regulate cellular architecture and motility.
\end{abstract}

Endocrine-Related Cancer (2012) 19 575-588

\section{Introduction}

RAP proteins are members of the RAS superfamily of small GTPases. Mammalian cells express five RAP proteins, RAP1A/B and RAP2A/B/C. RAP1 and RAP2 proteins exhibit $65 \%$ amino acid identity and are regulated by the same guanine nucleotide exchange factors (RAPGEFs) and GTPase activating proteins (RAPGAPs) (Ohba et al. 2000). RAPGEFs and RAPGAPs are multigene families (reviewed in Gloerich \& Bos (2011)). The RAPGAP family is comprised of RAP1GAP1 (and RAP1GAP1-II)/ RAP1GAP2, SPA-1/SIPA1, SPAR1,2,3, GAP1 ${ }^{\text {IP4BP }}$, RASAL, CAPRI and SynGAP, of which RAP1GAP is highly expressed in thyroid cells (Tsygankova et al. 2004). RAP1GAP is active on both RAP1 and RAP2, although it is more efficient on RAP1 (JanoueixLerosey et al. 1994, Ohba et al. 2000). RAPIGAP expression is progressively decreased in human thyroid, pancreas, colon and kidney tumors, and in melanomas. Multiple mechanisms of RAP1GAP downregulation have been identified. Loss of heterozygosity for the RAPlGAP gene (Zhang et al. 2006a, Nellore et al. 2009) and epigenetic regulation of RAPIGAP expression (Zheng et al. 2009, Zuo et al. 2010, Banerjee et al. 2011, Dong et al. 2011) have been reported. The wide array of tumors that exhibit progressive decreases in RAP1GAP expression, coupled with the many ways in which RAP1GAP expression is abolished, suggest that loss of RAP1GAP confers a selective, albeit unknown, advantage to tumor cells.

We were the first to report the downregulation of RAP1GAP in human thyroid tumors (Tsygankova et al. 2007). We went on to show that RAP1GAP expression is further decreased in papillary thyroid 
carcinomas (PTCs) compared with thyroid adenomas (Nellore et al. 2009). Other studies confirmed our findings and demonstrated a further decrease in RAP1GAP expression in invasive vs differentiated thyroid tumors (Zuo et al. 2010). Most studies have investigated the role of RAPIGAP in tumor cell lines selected to stably overexpress high levels of RAP1GAP, an approach that has yielded discrepant results (Zhang et al. 2006a,b, Mitra et al. 2008, Zheng et al. 2009, Freeman et al. 2010, Lin et al. 2010). Whether the observed effects are a direct consequence of RAP1GAP expression or secondary to the isolation of stable cell lines is unclear. We set out to explore the primary effects associated with restoring RAP1GAP expression to thyroid cancer cells. We determined that RAP1 and RAP2 are expressed in primary PTCs and that both proteins are active in thyroid cancer cell lines. To identify the cellular consequences of increased RAP activity, RAPIGAP was transiently expressed at levels just sufficient to inhibit endogenous RAP activity. Under these conditions, RAP1GAP impaired cell spreading and migration in five human thyroid cancer cell lines. Rather than inducing global effects on intracellular signaling pathways, RAP1GAP selectively impaired SRC-mediated phosphorylation of cytoskeletal proteins in spreading cells. SRC plays pivotal roles in transducing signals from activated growth factor receptors and integrins. SRC/focal adhesion kinase (FAK) complexes are pivotal regulators of cell/cell and cell/matrix adhesion, survival, migration, invasion, and metastasis. Our findings identify SRC as a potential target of RAP1GAP depletion and suggest that the downregulation of RAP1GAP enhances SRC/FAK-mediated signaling pathways that contribute to tumor progression.

\section{Materials and methods}

\section{Reagents}

RAP1GAP, RAP1, C3G, PY99, and actin antibodies were purchased from Santa Cruz (Santa Cruz, CA, USA). RAP2, 4G10, FAK, and paxillin antibodies were obtained from BD Transduction Laboratories (Bedford, MA, USA). ERK1/2, pERK (T202/Y204), AKT, pAKT (S473), p-Tyr-100, Src, and pSRC (Y416) antibodies were from Cell Signaling Technology (Danvers, MA, USA). pFAK (Y576) and p-paxillin (Y31) antibodies were from Invitrogen. PP2 and PP3 were purchased from Calbiochem (La Jolla, CA, USA) and SU6656 from Sigma-Aldrich. Collagen I was from BD Biosciences (Bedford, MA, USA).

\section{Immunohistochemistry}

Formalin-fixed paraffin-embedded blocks from archival specimens were stained for RAP1GAP, RAP1, and RAP2 using immunofluorescence labeling and conventional DAB staining. Prior to staining, the sections were de-paraffinized, stained with hematoxylin/eosin, and evaluated by a pathologist. The selected cases included two specimens of normal thyroid tissue, seven cases of PTC (five that contained normal thyroid), and seven cases of anaplastic thyroid carcinoma (ATC; three that contained normal thyroid). Fresh four micron serial sections were made and stained individually for RAP1GAP (Santa Cruz, sc-28189), RAP1 (BD Transduction Laboratories, \#610195), RAP2 (BD Transduction Laboratories, \#610215), or co-stained for RAP1GAP/RAP1 or RAP1GAP/RAP2. Negative (primary antibody replaced by nonimmune mouse or rabbit serum) and positive (normal thyroid tissue) controls were included in each run. Secondary antibodies, Alexa Fluor 488 or 594 conjugated anti-mouse and antirabbit IgG, were purchased from Invitrogen. Images were acquired using an Olympus BX60 fluorescence microscope and Spot Advanced Software.

\section{Cell culture}

BCPAP and KTC-1 PTC lines were obtained from Drs Rebecca E Schweppe and Bryan Haugen (University of Colorado, Denver) with permission from the researchers who provided these lines to them (Schweppe et al. 2008). TPC-1 cells were kindly provided by Dr Sissy Jhiang (The Ohio State University). ATC cell lines (Hth74, Hth83, and Hth104) were a generous gift from Dr N-E Heldin (University Hospital, Uppsala, Sweden; Dahlman et al. 2000). DNA profiling using the Identifier kit from Applied Biosystems (Carlsbad, CA, USA) confirmed that the BCPAP, TPC-1, Hth83, and Hth104 cell lines were unique and of thyroid origin.

\section{Western blotting}

Protein extracts were prepared using nonreducing sample buffer (NRSB; $62.5 \mathrm{mM}$ Tris (pH 6.8), $1 \mathrm{mM}$ sodium vanadate, $1 \mathrm{mM}$ sodium fluoride, $2 \% \mathrm{SDS}$, and $10 \%$ glycerol) and western blotting performed as described previously (Tsygankova et al. 2004).

\section{Cell transfection}

Expression vectors encoding GFP, constitutively active RAP2B (RAP2B63E, RAP2B64A, kindly provided by Dr Lawrence Quilliam, IUPUI) were transfected into TPC-1 cells using FuGENE 6 transfection reagent according to the manufacturer's instructions (Promega). 
After $48 \mathrm{~h}$, cells were suspended for $30 \mathrm{~min}$ and then plated onto collagen-coated dishes for various times. Total cell lysates were prepared and equal amounts of cell protein were analyzed for tyrosine phosphorylation of FAK and paxillin and ERK phosphorylation.

\section{Viral infection}

Cells were infected for $4 \mathrm{~h}$ in serum-free medium and then maintained in growth medium for $24 \mathrm{~h}$. HA-RAP1GAP and $\beta$-galactosidase adenoviruses were constructed using the AdEasy vector system (Qbiogene, Carlsbad, CA, USA) as described previously (Tsygankova et al. 2007). Cells were infected with $R A P I G A P$ and $L A C Z$ viruses at an equal multiplicity of infection (MOI).

\section{RAP activity}

RAP activity was assessed in pull-down assays using the RALGDS-RAP binding domain fused to glutathione S-transferase (GST) as described previously (Tsygankova et al. 2004). Equal amounts of total cell protein were used to normalize RAP activity across cell lines.

\section{Wound assays}

Tissue culture plates marked with a line down the center were coated with collagen I $(30 \mu \mathrm{g} / \mathrm{ml})$ in $0.01 \%$ acetic acid for $2 \mathrm{~h}$ at $4{ }^{\circ} \mathrm{C}$ and washed twice with PBS at room temperature. Confluent monolayers of control and infected cells (at $24 \mathrm{~h}$ postinfection) were wounded perpendicularly to the line, the medium changed to remove floating cells and the cells imaged immediately and at various times thereafter using a Nikon Eclipse TE2000 microscope. Five to six areas along the wound were measured (using Image J Software) and the area at the conclusion of the experiment compared with that at $0 \mathrm{~h}$, which was set to 1.0 .

\section{Cell spreading}

Cells were trypsinized, the trypsin inactivated and the cells held in suspension in serum-free medium for $30 \mathrm{~min}$ prior to plating. Equal numbers of cells were plated onto collagen I-coated dishes and analyzed as described in the text.

\section{Statistical analyses}

All experiments were performed three or more times with similar results. Statistical analyses were performed using Excel 2007 Software. Data are presented as mean \pm S.D. and significance was assessed by $t$-test. A $P$ value of $<0.05$ was considered to be statistically significant.

\section{Results}

\section{Alterations in RAP1GAP, RAP1, and RAP2 expression in primary thyroid tumors}

RAP protein expression in the thyroid gland and in thyroid tumors has not been previously examined. Human tissue specimens were subjected to highly sensitive fluorescence-based immunohistochemical staining for RAP1, RAP2, and RAP1GAP. As previously reported (Tsygankova et al. 2007, Nellore et al. 2009), RAP1GAP was abundantly expressed in human thyroid follicular cells (Fig. 1A). Surprisingly, RAP1 was not detected in follicular cells although it was present in red blood cells in the surrounding tissue. RAP2 was highly expressed in follicular epithelial cells. Moreover, RAP2 and RAP1GAP were co-expressed in the same cells, suggesting that RAP1GAP regulates RAP2 activity in normal thyroid cells. Additional sections from the same specimens were stained individually for RAP1GAP, RAP1, and RAP2 and processed using conventional immunohistochemistry (Fig. 1B). This analysis confirmed that normal thyrocytes express RAP1GAP and RAP2, but little RAP1.

To determine if there were alterations in RAP protein expression in thyroid tumors, RAP1 and RAP2 expression were analyzed in seven PTCs and seven ATCs. As expected, the expression of RAP1GAP was decreased in PTCs (Fig. 2A) and ATCs (Fig. 3) compared with adjacent normal thyroid tissue. Interestingly, RAP1 protein levels were upregulated in papillary thyroid tumors compared with normal thyroid cells (Fig. 2A and B). RAP2 expression was retained in PTCs. Immunofluorescence staining revealed that both RAP proteins were detected in the cytoplasm and at the plasma membrane in PTCs (Fig. 2B). These results support the notion that depletion of RAP1GAP in human tumors results in the activation of RAP1 and RAP2. In further support of this idea, silencing the expression of RAPIGAP in the HT29 colon cancer cell line was sufficient to increase RAP1 and RAP2 activity (Tsygankova et al. 2010). The analysis of ATCs yielded unexpected results. Fluorescence staining for RAP1 was markedly reduced, while RAP2 staining was retained in these tumors (Fig. 3).

To validate these observations, a set of eight duplicate sections from the subset of tumors that contained regions of normal thyroid cells were subjected to conventional immunohistochemistry and scored in a blinded fashion. Two samples of normal thyroid were included in this analysis. Table 1 shows that RAP1GAP expression was decreased in tumors compared with adjacent normal thyroid, in agreement 

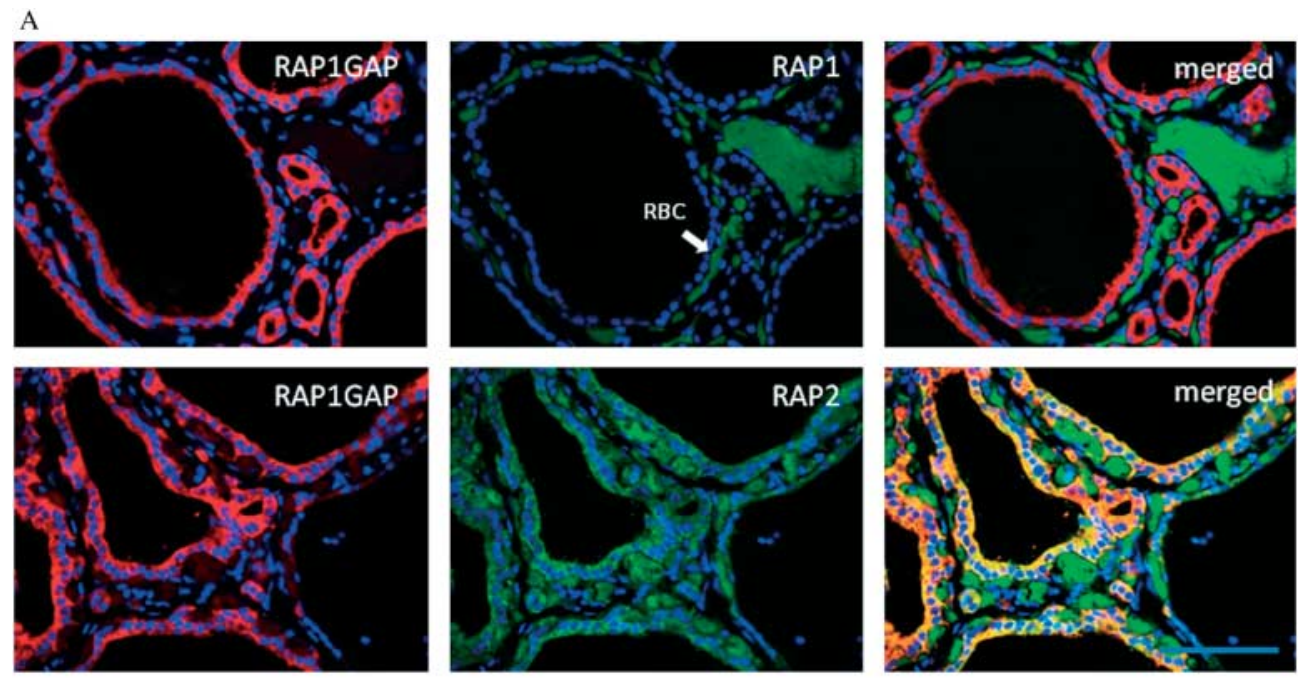

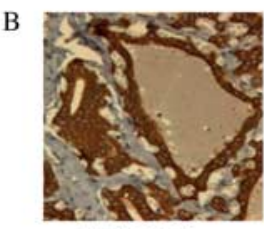

RAP1GAP

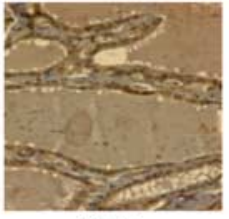

RAP1

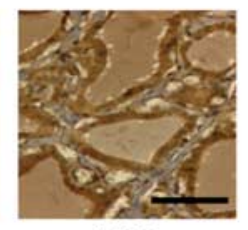

RAP2

Figure 1 RAP1GAP, RAP1, and RAP2 expression in the thyroid gland. (A) Freshly cut sections of normal thyroid tissue were co-stained for RAP1GAP/RAP1 or RAP1GAP/RAP2 and analyzed by fluorescence microscopy. RAP1 expression in red blood cells is indicated by an arrow. Merged images are shown in the right panels. (B) Serial sections of the same sample were analyzed by DAB staining. Magnification, $400 \times$; scale bar represents 50 microns.

with previous reports (Tsygankova et al. 2007, Nellore et al. 2009, Zuo et al. 2010). RAP1 was not detected in normal thyroid cells or in regions of normal thyroid tissue in thyroid tumors, although it was detected in tumor cells. On the other hand, RAP2 was consistently expressed in normal thyroid cells and in thyroid tumors. Compared with PTCs, RAP1 expression was decreased in ATCs, while RAP2 expression was largely unchanged. Collectively, these data suggest that RAP2 is the physiological target of RAP1GAP in normal thyroid cells and is likely to play a role in thyroid cancer.

\section{RAP1 and RAP2 activity in thyroid cancer cell lines}

In parallel with the studies in human tumors, RAP1GAP, RAP1, and RAP2 protein expression was analyzed in a panel of human thyroid cancer cell lines. Differentiated Wistar rat thyroid (WRT) cells were included as a control for RAP1GAP protein expression (Tsygankova et al. 2004). RAP1GAP protein levels were far lower in the human thyroid cancer cell lines compared with differentiated rat thyroid cells
(Fig. 4A). Low levels of RAP1GAP were detected in the PTC cell lines, BCPAP, KTC-1, and TPC-1. As these cell lines harbor different activating mutations, downregulation of RAP1GAP was not associated with a specific mutational event (Schweppe et al. 2008). RAP1GAP protein expression was further decreased in ATC (Hth83, Hth104, Hth74, and SWI736) compared with PTC cell lines, similar to reports in human thyroid tumors (Zuo et al. 2010). The RAPGEF C3G was expressed at higher levels in the human thyroid tumor cell lines compared with differentiated rat thyroid cells (Fig. 4A). However, no changes in $\mathrm{C} 3 \mathrm{G}$ expression were observed between PTC and ATC cell lines, suggesting that the expression of RAPIGAP is selectively modulated in human thyroid tumors.

Consistent with the staining patterns observed in primary PTCs, both RAP1 and RAP2 proteins were detected in the PTC cell lines (Fig. 4A). Unlike primary ATCs where RAP1 was not detected, RAP1 protein was detected in the ATC cell lines. Similar to the primary tumors, the expression of RAP1 was decreased in ATC vs PTC cell lines. To determine whether one or both RAP proteins were active in the thyroid cancer cell lines, RAP activity was monitored. 
A
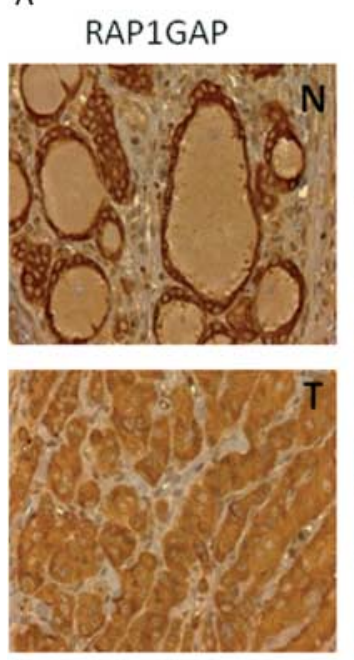

B

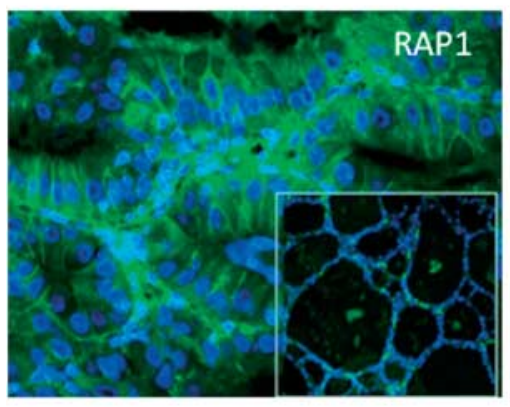

RAP1
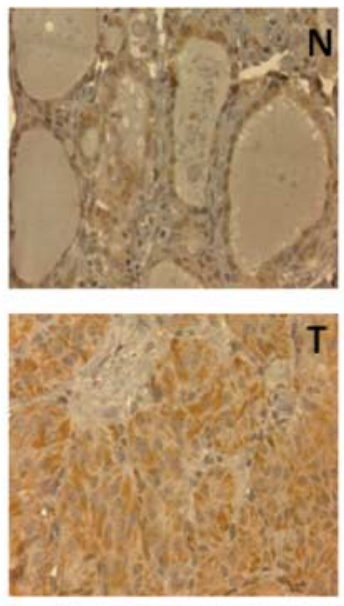

$\mathrm{T}$
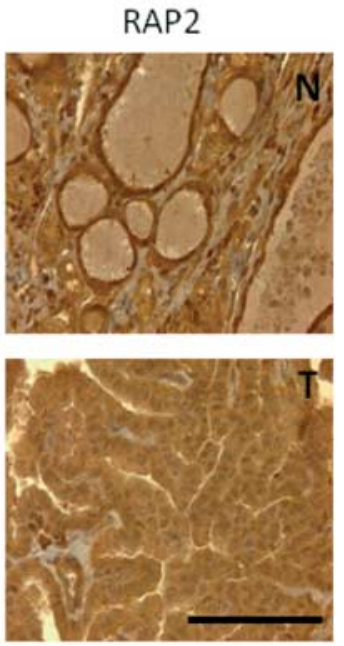

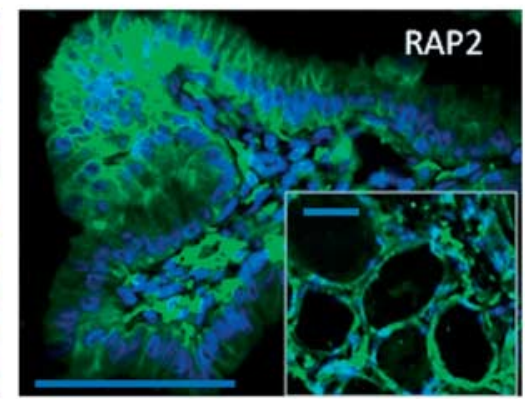

PTC

Figure 2 RAP1 and RAP2 expression in PTC. (A) Staining for RAP1GAP, RAP1, and RAP2 in serial sections from the same PTC is shown. Upper panel $(\mathrm{N})$ shows staining in adjacent normal thyroid tissue and lower panel $(\mathrm{T})$ in tumor tissue. (B) Two PTCs that contained regions of normal thyroid cells were stained for RAP1 and RAP2 and analyzed by fluorescence microscopy. Magnification $400 \times$; scale bar represents 50 microns. Inset (magnification, $200 \times$ ) shows RAP staining in normal thyroid cells from the same specimens.

Compared with HT29 colon cancer cells that express endogenous RAP1GAP, RAP1, and RAP2 activity was increased in PTC and ATC cell lines (Fig. 4B and C). RAP2 appears to be more abundant than RAP1 in the thyroid cancer cell lines, although differences in the quality of the antibodies used to detect RAP1 vs RAP2 cannot be excluded. Nonetheless, when compared with total levels of RAP expression, more RAP2 was active compared with RAP1. This is likely due to the relative insensitivity of RAP2 to RAP1GAP compared with RAP1 (Janoueix-Lerosey et al. 1994, Ohba et al. 2000). The RAP2 antibody employed in these studies recognizes RAP2A, B, and C. To determine which RAP2 proteins were expressed in thyroid cancer cells, acute silencing experiments were conducted. Transfection with three different pools of RAP2A-directed siRNAs had no effect on RAP2 expression (Fig. 4D).
Combined transfection with three different pools of RAP2B- and RAP2C-directed siRNAs reduced RAP2 protein levels. Although we cannot exclude the possibility that all three pools of the RAP2A siRNAs were nonfunctional, these results clearly indicate that RAP2B and RAP2C are expressed in human thyroid tumor cell lines.

\section{RAP1GAP impairs cell migration in the absence of effects on ERK and AKT activity}

To identify the cellular effects mediated through increased RAP activity, RAPIGAP was transiently expressed at the lowest level sufficient to inhibit RAP2 activity. PTC and ATC cell lines were infected with $\beta$-galactosidase or RAP1GAP-expressing adenoviruses and RAP2 activity monitored at $24 \mathrm{~h}$ postinfection. 

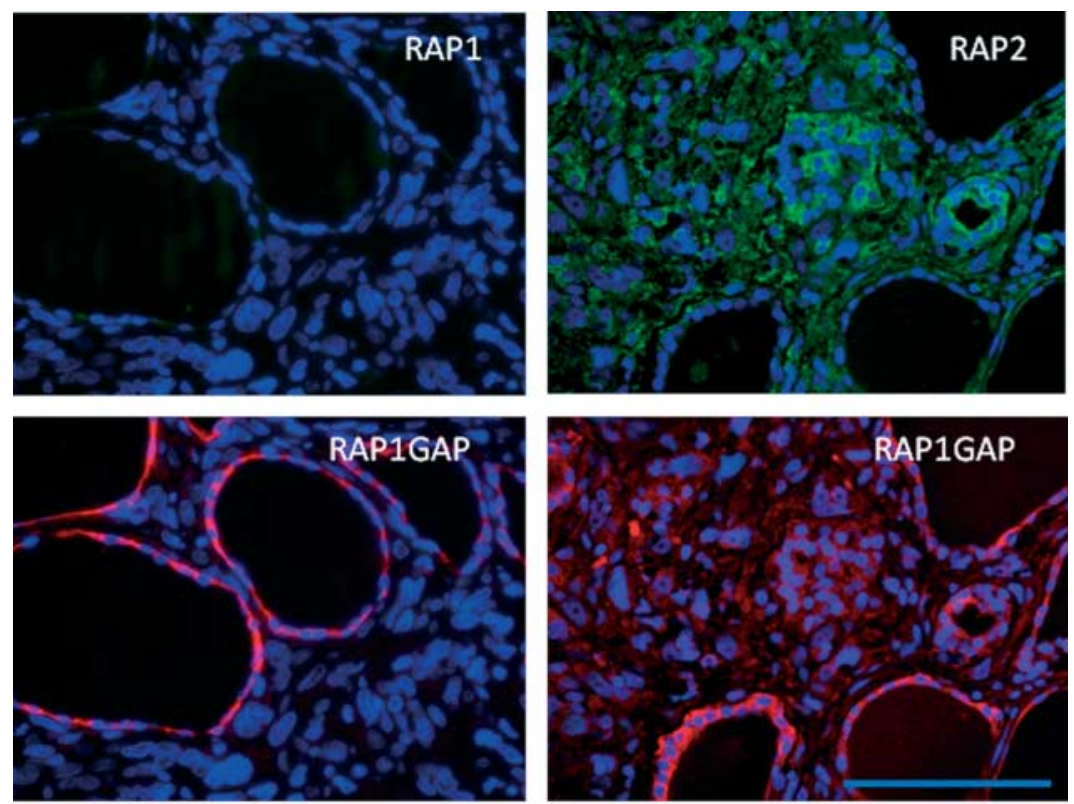

ATC

Figure 3 RAP1GAP, RAP1, and RAP2 expression in ATC. Freshly cut slices of ATC containing normal thyroid tissue were co-stained for RAP1GAP/RAP1 or RAP1GAP/RAP2 and analyzed by fluorescence microscopy. Magnification, $400 \times$; scale bar represents 50 microns.

Expression of RAP1GAP dose dependently inhibited RAP2 activity in the absence of effects on RAP2 expression (Fig. 5A). Expression of $\beta$-galactosidase had no effect on RAP2 activity (Fig. 5B). The lowest dose of the RAPIGAP adenovirus that was sufficient to block RAP2 activity in each cell line was used for subsequent experiments.

Cell lines selected to stably express high levels of RAP1GAP exhibit impaired migration (Zhang et al. 2006a, Zheng et al. 2009, Freeman et al. 2010, Lin et al. 2010). To assess whether transient overexpression of RAP1GAP was sufficient to impair cell motility, cells were infected with $L A C Z$ or RAPIGAP-expressing adenoviruses and wound closure assays conducted. Cells plated onto collagen I-coated dishes were grown to confluence, wounded, and imaged at time zero and again after 9-29 $\mathrm{h}$ depending on the cell line. RAP1GAP delayed wound closure in all of the cell lines (Figs 6A and 7A). Quantitative measurements of wound area revealed that RAP1GAP significantly impaired wound closure in both PTC (Fig. 6B) and ATC (Fig. 7B) cells. These

Table 1 RAP and RAP1GAP staining in normal human thyroid cells and in thyroid tumors

\begin{tabular}{|c|c|c|c|c|c|c|c|}
\hline \multirow[b]{2}{*}{ Identifier } & \multirow[b]{2}{*}{ Diagnosis } & \multicolumn{2}{|c|}{ RAP1GAP } & \multicolumn{2}{|c|}{ RAP1 } & \multicolumn{2}{|c|}{ RAP2 } \\
\hline & & Normal & Tumor & Normal & Tumor & Normal & Tumor \\
\hline MSB2952 & Normal & ++++ & $\mathrm{N} / \mathrm{A}$ & - & $\mathrm{N} / \mathrm{A}$ & +++ & $\mathrm{N} / \mathrm{A}$ \\
\hline 1705 & Normal & +++ & $\mathrm{N} / \mathrm{A}$ & - & $\mathrm{N} / \mathrm{A}$ & ++ & $\mathrm{N} / \mathrm{A}$ \\
\hline MSB1868 & PTC & +++ & + & - & ++ & ++ & +++ \\
\hline MSB1880 & PTC & ++++ & ++ & - & + & ++ & +++ \\
\hline MSB1896 & PTC & +++ & ++ & - & + & + & ++ \\
\hline MSB1901 & PTC & ++ & + & - & + & +++ & ++ \\
\hline MSB3297 & PTC & +++ & ++ & - & ++ & ++ & ++ \\
\hline MSB3318 & ATC & ++++ & - & - & - & ++ & + \\
\hline MSB2213 & ATC & +++ & +++ & - & + & +++ & ++ \\
\hline OTB1237 & ATC & +++ & $-1+$ & - & - & +++ & ++ \\
\hline
\end{tabular}

N/A, not applicable; PTC, papillary thyroid carcinoma; ATC, anaplastic thyroid carcinoma. 
A

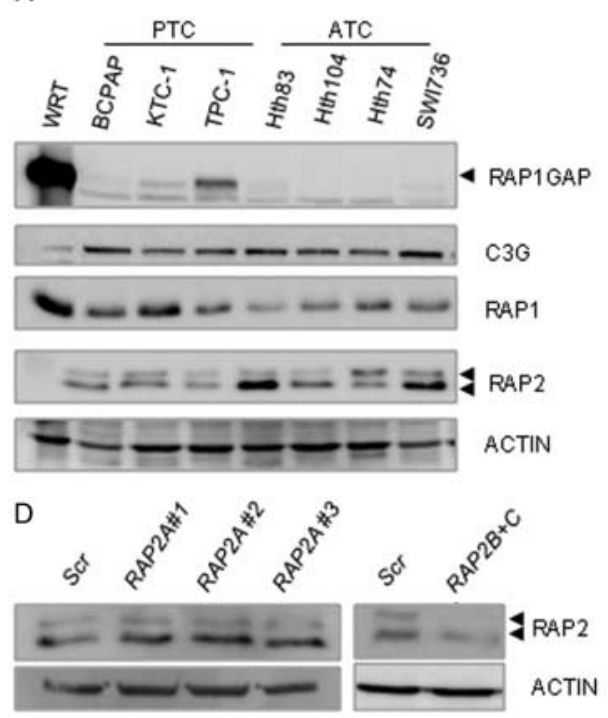

B

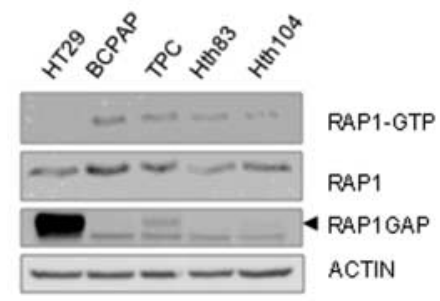

C

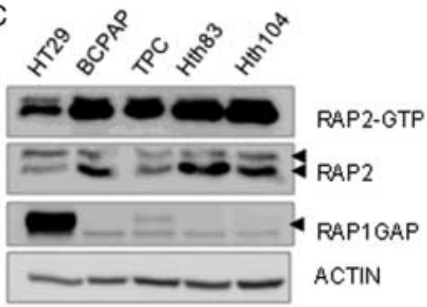

Figure 4 RAP expression and activity in thyroid cancer cell lines. (A) RAP1GAP, C3G, RAP1, and RAP2 expression were analyzed in BCPAP, KTC-1, TPC-1 (PTC) and Hth83, Hth104, Hth74, and SWI736 (ATC) cell lines. Differentiated WRT cells were included as a positive control for RAP1GAP. Western blotting for actin confirmed equal protein loading. The exposure time for the RAP1 western blot was longer than that for RAP2. (B and C) RAP1 and RAP2 activity (RAP1-GTP and RAP2-GTP) were analyzed by pull-down assays in growing cells. RAP1, RAP2, and RAP1GAP expression in whole cell lysates is shown. Western blotting for actin documented equal protein loading. The same exposure times (40 s) for RAP1 and RAP2 were used for the images shown in (B) and (C). (D) Gene silencing was used to characterize RAP2 protein expression in BCPAP cells. Three independent pools of RAP2A-directed siRNAs did not reduce RAP2 protein levels, whereas RAP2B- and RAP2C-directed siRNAs reduced RAP2 expression.

data fortify studies showing that the overexpression of RAP1GAP impaired the migration of TPC-1 and Hth83 cells as well as that of a follicular thyroid cancer cell line, FTC-133 (Tsygankova et al. 2007, Zuo et al. 2010).

ERK and AKT activity play important roles in thyroid cancer cell motility (Knauf \& Fagin 2009, Saji \& Ringel 2010, Carlomagno \& Santoro 2011, Viglietto et al. 2011). Interestingly, under conditions where migration was impaired, overexpression of RAP1GAP did not alter the activity of either protein kinase in any of the five cancer cell lines (Fig. 7C). Thus, RAP1GAP inhibits other signaling pathways and/or induces localized effects on discrete pools of signaling molecules.

\section{RAP1GAP impairs cell spreading}

RAP1 is an important regulator of cell/matrix and cell/cell adhesion (Bos 2005). Far less is known about the roles of RAP2. To further explore the cellular effects mediated through RAP, effects on cell spreading were analyzed. PTC and ATC cell lines were infected with $L A C Z$ or RAPIGAP-expressing adenoviruses. After $24 \mathrm{~h}$, the cells were released by trypsinization, held in suspension for $30 \mathrm{~min}$ and plated onto collagen I-coated dishes for various times.
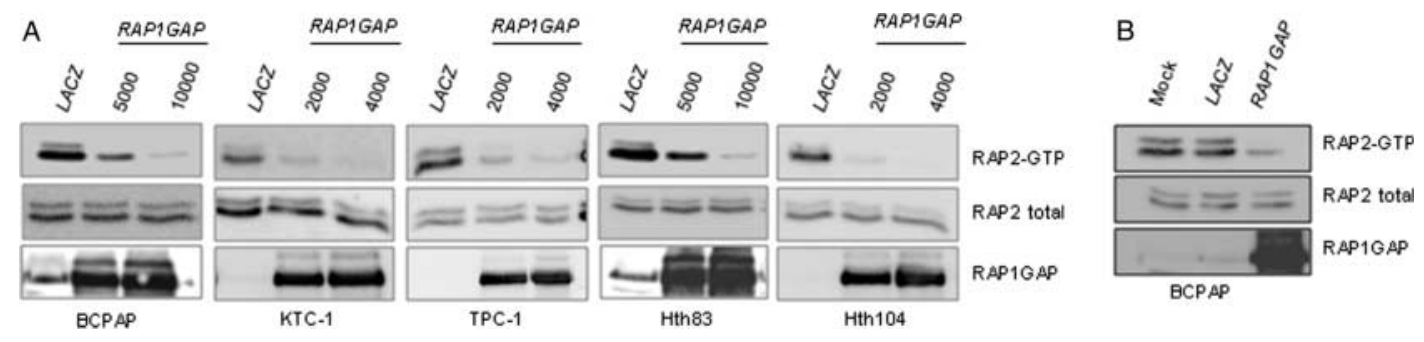

Figure 5 Overexpression of RAP1GAP inhibits RAP2 activity. (A) PTC (BCPAP, KTC-1, and TPC-1) and ATC (Hth83 and Hth104) cell lines were infected with RAP1GAP or LACZ adenoviruses at the MOI indicated (particles/cell) and RAP2 activity monitored after $24 \mathrm{~h}$. (B) Infection with LACZ adenovirus had no effect on basal levels of RAP2 activity in BCPAP cells. 

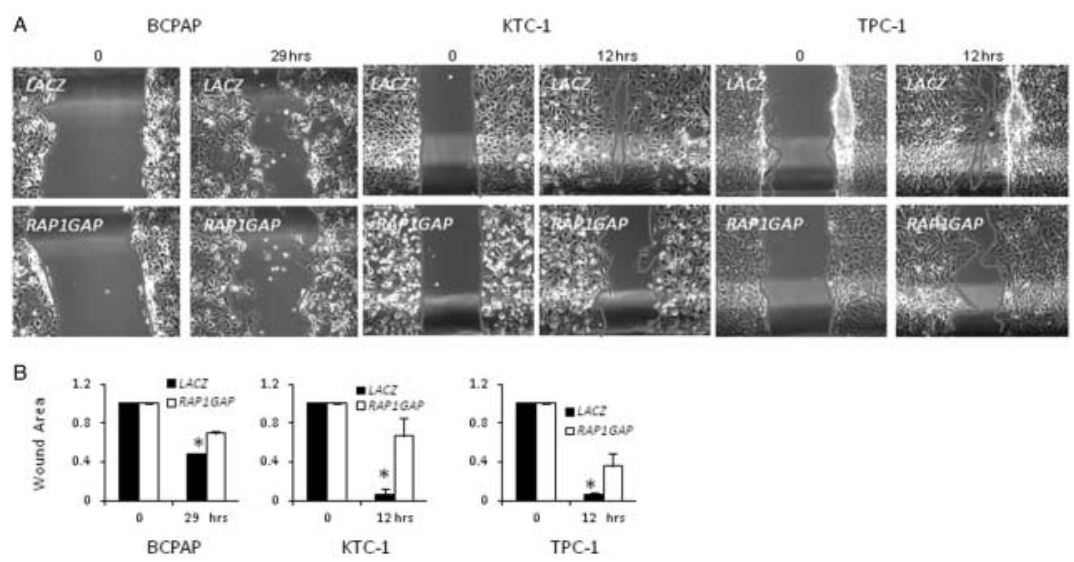

Figure 6 RAP1GAP inhibits serum-stimulated cell migration in PTC cell lines. (A) BCPAP, KTC-1, and TPC-1 cells were infected with $L A C Z$ or RAP1GAP-expressing adenoviruses for $24 \mathrm{~h}$. Confluent monolayers were wounded with a pipette tip and images acquired immediately and at the times indicated. Lines indicate the borders of the areas that were measured. (B) Measurements of cell area from three independent experiments confirmed that RAP1GAP significantly $\left({ }^{\star} P<0.01\right)$ decreased wound closure. Wound area at time zero was set to 1.0. The area within the lines shown in the images, together with four to five additional areas along each wound, was quantified.

Cell area increased over time in $L A C Z$ virus-infected cells (Fig. 8A). Expression of RAP1GAP significantly delayed cell spreading in all of the cell lines.

Adhesion and spreading on the extracellular matrix initiate a cascade of signaling events characterized by alterations in protein tyrosine phosphorylation. To explore the mechanism through which RAPlGAP impairs cell spreading, lysates prepared from suspended cells and from cells acutely plated onto collagen I-coated dishes were analyzed for global changes in protein tyrosine phosphorylation. Plating of cells onto collagen I-coated dishes induced the phosphorylation of two major protein species (Fig. 8B, proteins marked by * in $L A C Z 30 \mathrm{~min}$ ). Strikingly, the
A
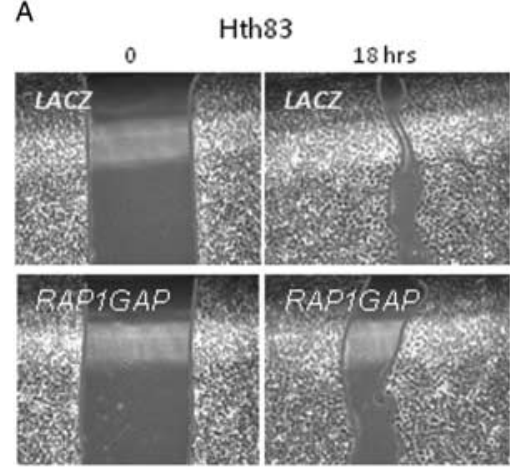

B

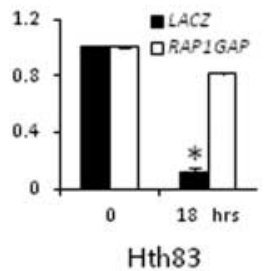

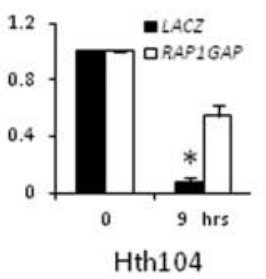

Hth104
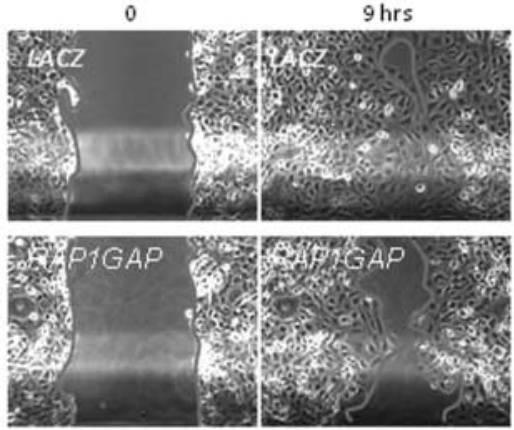

C

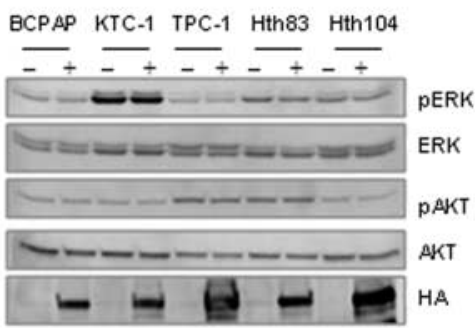

Figure 7 RAP1GAP inhibits migration in the absence of inhibitory effects on ERK activity. (A) Hth83 and Hth104 cells were infected with $L A C Z$ or RAP1GAP-expressing adenoviruses and cell migration analyzed after $24 \mathrm{~h}$ as described in legend of Fig. 6. (B) Results from three independent migration experiments are shown. RAP1GAP significantly $\left({ }^{\star} P<0.01\right)$ decreased wound closure. (C) At $24 \mathrm{~h}$ postinfection, cells were disrupted and total cell proteins analyzed by western blotting for pERK, total ERK, pAKT, total AKT, and HA-RAP1GAP. 


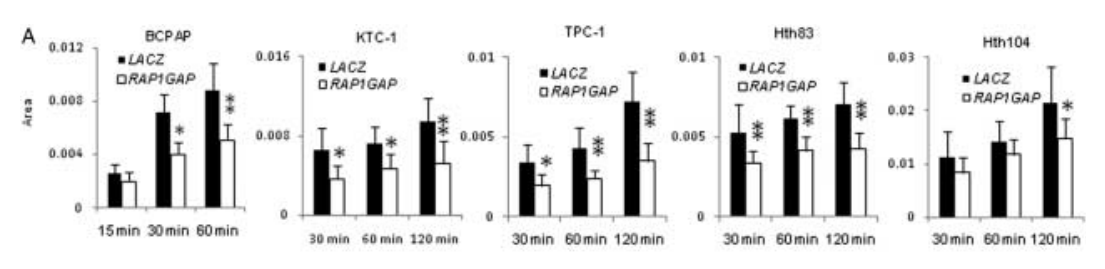

B

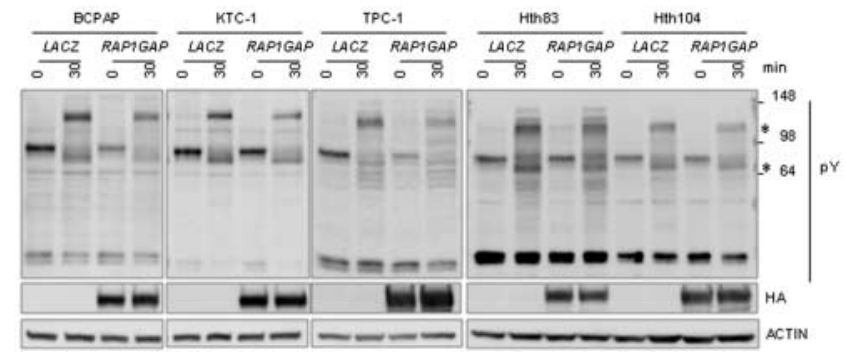

Figure 8 RAP1GAP inhibits cell spreading and protein tyrosine phosphorylation. (A) PTC and ATC cell lines were infected with $L A C Z$ or RAP1GAP-expressing adenoviruses for $24 \mathrm{~h}$. Cells were released, held in suspension for $30 \mathrm{~min}$, and plated onto collagen-coated dishes in the absence of serum for the times indicated. Cell area was measured using Image J Software. RAP1GAP significantly impaired cell spreading $\left({ }^{*} P<0.05,{ }^{* *} P<0.01\right)$. (B) Suspended cells $(0)$ and cells plated onto collagen-coated dishes for 30 min $(30)$ were disrupted and total cell proteins analyzed by western blotting with anti-phosphotyrosine (4G10) antibody (pY). The position of molecular weight markers $(\mathrm{kDa})$ is shown. Asterisks $\left(^{*}\right)$ denote protein species that are increased in phosphorylation upon plating. Expression of HA-RAP1GAP is shown. Western blotting for actin confirmed equal protein loading.

phosphorylation of both species was decreased by RAP1GAP in the PTC cell lines.

\section{RAP1GAP impairs tyrosine phosphorylation of FAK and paxillin}

Integrin activation induces the autophosphorylation/activation of FAK. As RAP1GAP impaired tyrosine phosphorylation of a protein species is similar in size to FAK $(125 \mathrm{kDa})$, the effects of RAP1GAP on FAK phosphorylation were assessed using a panel of phospho-specific FAK antibodies. In the PTC cell lines, RAP1GAP delayed FAK phosphorylation at Y576, a site that when phosphorylated by SRC enhances FAK activity (Fig. 9A). We surmised that the $68 \mathrm{kDa}$ protein could be paxillin, an SRC substrate that localizes to focal adhesions. RAP1GAP decreased phosphorylation of paxillin at Y31, a site that can be phosphorylated by SRC. Importantly, total levels of FAK and paxillin were not altered by RAP1GAP. The inhibition of tyrosine phosphorylation on FAK and paxillin by RAP1GAP was highly consistent. Figure 9B shows that RAP1GAP significantly delayed tyrosine phosphorylation of FAK and paxillin in the PTC, but not in ATC cell lines (Fig. 9B). As was seen in growing cells, expression of RAPIGAP did not impair ERK (Fig. 9A and B) or AKT (data not shown) phosphorylation in spreading cells.

These data suggest that RAP activity is required for the phosphorylation of FAK and paxillin. Given that
RAP2 comprises the majority of RAP activity in thyroid cancer cell lines, we examined whether the expression of constitutively active RAP2 enhanced tyrosine phosphorylation of FAK and paxillin. Cells expressing activated RAP2B were plated onto collagen-coated dishes and tyrosine phosphorylation of FAK and paxillin assessed by western blotting. Compared with control GFP-expressing cells, phosphorylation of FAK and paxillin was reduced by expression of active RAP2B while ERK phosphorylation was not affected (Fig. 9C). This finding suggests that the cycling of RAP2 activity is required for reorganization of the actin cytoskeleton in spreading cells.

\section{RAP1GAP impairs SRC activity}

Autophosphorylated FAK recruits SRC to focal adhesions where SRC phosphorylates FAK and paxillin. Blockade of SRC activity reduced tyrosine phosphorylation of FAK and paxillin in spreading cells (Fig. 10A). To assess whether RAP1GAP inhibited SRC activity, western blotting using an antibody specific for active SRC (Y416p) was performed. Unexpectedly, SRC phosphorylation was increased in suspended cells and declined in cells plated onto collagen-coated dishes (Fig. 10A, compare control in suspended and plated cells). This was not restricted to a single cell line as SRC activity was similarly regulated in all of the thyroid cancer cell lines (Fig. 10B). 


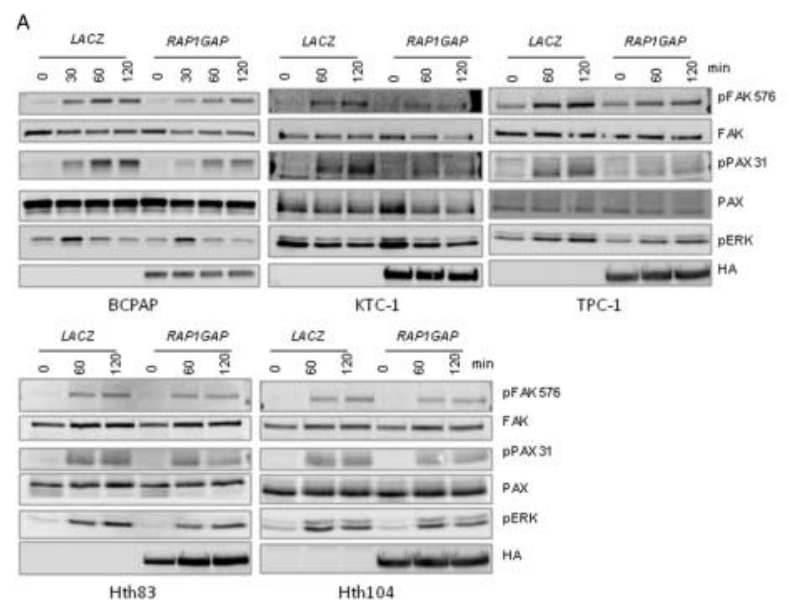

B
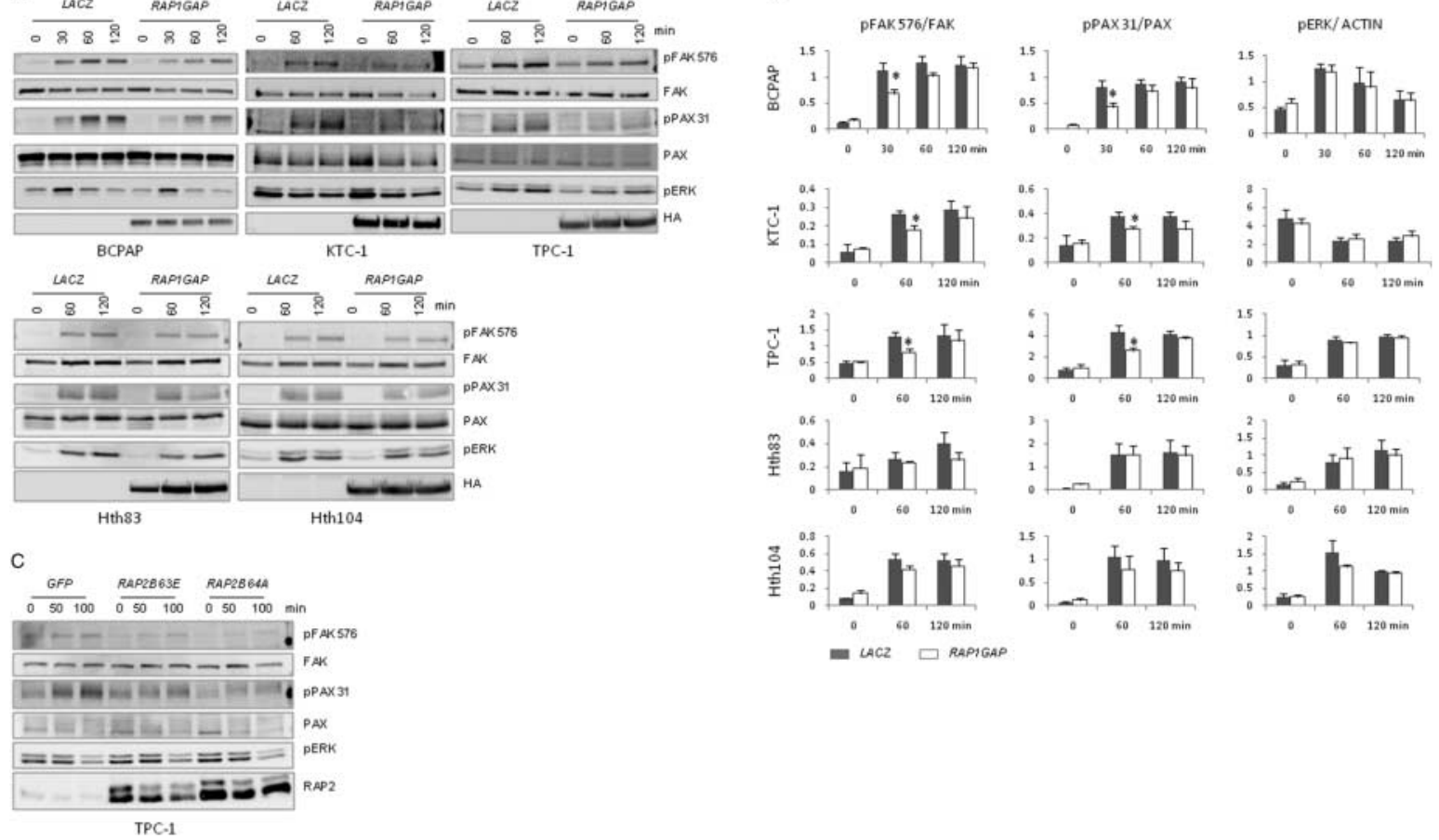

Figure 9 RAP1GAP impairs FAK and paxillin phosphorylation. (A) RAP1GAP- and LACZ-infected cells were suspended for 30 min and plated onto collagen-coated dishes in the absence of serum for the times indicated. Cells were disrupted and total cell proteins analyzed by western blotting for pFAK, total FAK, p-paxillin, total paxillin, pERK, and HA-RAP1GAP. (B) The results from three independent spreading experiments in each cell line are shown. FAK phosphorylation normalized to total FAK, paxillin phosphorylation normalized to total paxillin, and ERK phosphorylation normalized to actin are shown. RAP1GAP significantly $\left({ }^{*} P<0.05\right)$ delayed FAK and paxillin phosphorylation in the PTC, but not ATC cell lines. ERK phosphorylation was unaffected by RAP1GAP. (C) TPC-1 cells were transfected with constructs expressing constitutively active RAP2B (RAP2B63E and RAP2B64A) or GFP as a control. Cells were suspended and then plated onto collagen-coated dishes for 50 and 100 min. Total cell lysates were prepared and subject to western blotting for tyrosine phosphorylation on FAK and paxillin, and for ERK phosphorylation. RAP2 expression is also shown.

We confirmed that SRC phosphorylation reflected kinase activity. Treatment with two structurally distinct SRC kinase inhibitors (SU6656, PP2) impaired SRC phosphorylation in suspended cells (Fig. 10A). To determine if RAP1GAP impaired SRC activity, the effects of RAP1GAP on SRC phosphorylation in suspended cells were analyzed. With the exception of KTC-1 cells, expression of RAPIGAP impaired SRC phosphorylation in the PTC cell lines (Fig. 10B and C). Similar to the effects on FAK and paxillin, RAP1GAP did not inhibit SRC activity in ATC cells. These data demonstrate that the phosphorylation of SRC, as well as of two SRC substrates, is sensitive to the levels of RAP1GAP in PTC cell lines.

\section{SRC activity is required for thyroid cancer cell spreading and migration}

The reduction in SRC activity by RAP1GAP suggested that the inhibition of cell spreading and motility observed in RAP1GAP-expressing PTC cells could be mediated through inhibition of SRC. In support of this idea, SRC inhibition impaired the ability of BCPAP cells to spread (Fig. 10D) and migrate (Fig. 10E) on collagen I. Collectively, these data suggest that the downregulation of RAP1GAP in human thyroid tumors has the potential to enhance SRC-dependent effects on cell spreading and migration.

\section{Discussion}

The goal of these studies was to explore the cellular consequences associated with RAP1GAP downregulation in human thyroid tumors. To that end, a panel of human thyroid cancer cell lines was screened for the expression of RAPIGAP and its best known targets, RAP1 and RAP2. As expected, the expression of RAPIGAP was markedly decreased in PTC cell lines compared with differentiated rat thyroid cells, and further decreased in ATC cell lines. Both RAP1 and RAP2 were expressed in the thyroid cancer cell lines. 
A

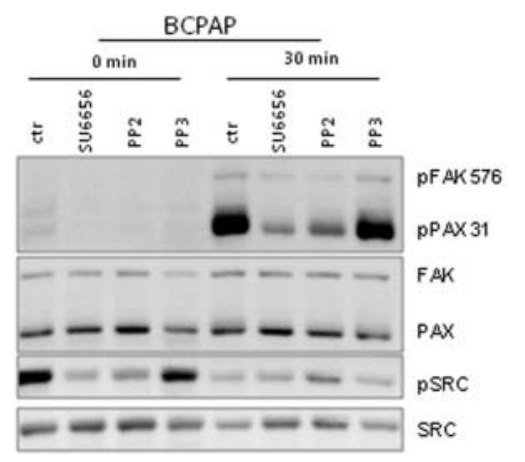

D

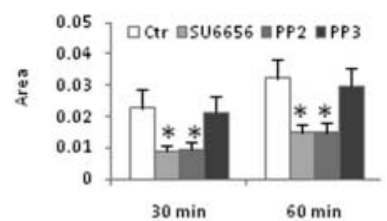

E

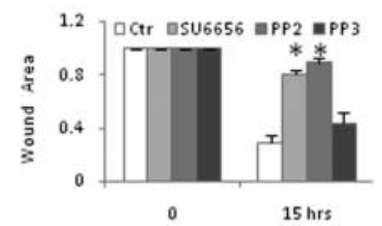

B
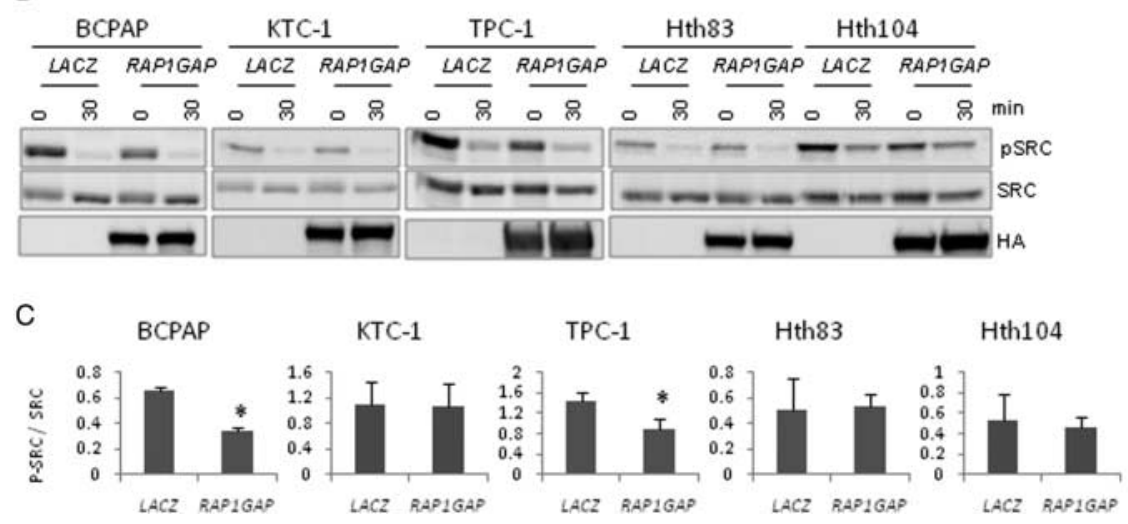

Figure 10 RAP1GAP impairs SRC activity in suspended cells. (A) BCPAP cells were pretreated with the SRC inhibitors SU6656, PP2, the inactive analog PP3 (all at $10 \mu \mathrm{M}$ ), or vehicle (control, ctr) for $30 \mathrm{~min}$, released, held in suspension for 30 min and plated onto collagen-coated dishes for $30 \mathrm{~min}$. Cells were disrupted and total cell proteins analyzed by western blotting for $\mathrm{pFAK}, \mathrm{p}$-paxillin, total FAK, total paxillin, pSRC, and total SRC. (B) PTC and ATC cell lines were infected with LACZ or RAP1GAP-expressing adenoviruses for $24 \mathrm{~h}$. Cells were released, held in suspension for $30 \mathrm{~min}$, and plated onto collagen-coated dishes for $30 \mathrm{~min}$. Cells were disrupted and total cell proteins analyzed by western blotting for pSRC, total SRC, and HA-RAP1GAP. (C) Results from three independent experiments in which SRC phosphorylation was normalized to SRC expression are shown. RAP1GAP significantly $\left({ }^{\star} P<0.01\right)$ impaired SRC phosphorylation in BCPAP and TPC-1 cells. (D) BCPAP cells were pretreated with SU6656, PP2, PP3, or vehicle, equal numbers of cells plated onto collagen-coated dishes for 30 and $60 \mathrm{~min}$ and cell area measured. Inhibition of SRC significantly $\left({ }^{*} P<0.01\right)$ delayed cell spreading. (E) BCPAP cells treated as in (D) were wounded and images acquired immediately and after $15 \mathrm{~h}$. Inhibition of SRC significantly $\left({ }^{*} P<0.01\right)$ impaired wound closure.

To assess whether one or both proteins were active, RAP1 and RAP2 activity was monitored. Assuming that the antibodies employed detect GTP- and GDP-bound RAP with similar affinities, far more RAP2 was active compared with RAP1. This is the first evidence of increased RAP2 activity in thyroid cancer cells. This has significant implications as RAP1 and RAP2 signal through both shared and discrete downstream signaling molecules (Spilker \& Kreutz 2010).

To assess the physiological significance of this observation, the expression of RAP1 and RAP2 in the human thyroid gland and in primary thyroid tumors was investigated. Interestingly, RAP1 protein was not detected in normal human thyroid follicular cells. In contrast, RAP2 was readily detected. Moreover, RAP2 and RAP1GAP were co-expressed in the same cells, identifying RAP2 as the primary target of RAP1GAP in human thyroid cells. Strikingly different results were observed in primary PTCs. Not only were both RAP1 and RAP2 expressed in these tumors, both proteins were present at the plasma membrane, a site where activated RAP is localized (Bivona et al. 2004). These data suggest that the depletion of RAPIGAP results in the upregulation and/or stabilization of RAP1, in addition to the activation of both RAP1 and RAP2. This is the first analysis of RAP1 and RAP2 protein expression in the human thyroid gland. Consistent with our findings, a recent report showed that RAP1B and $\mathrm{RAP} 2 \mathrm{~A} / \mathrm{B} / \mathrm{C}$ message levels were increased in PTCs compared with normal thyroid cells (van Staveren et al. 2012). Upregulation of RAP2A message levels in follicular thyroid carcinomas (FTCs) compared with 
adenomas (Chevillard et al. 2004) and in the invasive regions of FTCs (Prabakaran et al. 2011) has been reported. Collectively, these data support an important role for both RAP1 and RAP2 in thyroid tumors.

To elucidate potential advantages conferred to thyroid tumors by depletion of RAP1GAP, RAPIGAP was transiently expressed at the lowest level that is sufficient to block endogenous RAP2 activity. Under these conditions, RAP1GAP impaired the ability of thyroid cancer cells to spread and migrate on collagen I. Despite the crucial roles played by ERK and AKT in thyroid cancer cell migration and invasion (Knauf \& Fagin 2009, Saji \& Ringel 2010, Carlomagno \& Santoro 2011, Viglietto et al. 2011), RAP1GAP did not inhibit ERK or AKT activity. In addition, the expression of activated RAP2 did not increase ERK activity. This was not surprising to us as the effects of activated RAP on ERK activity are controversial (reviewed in Raaijmakers \& Bos (2009)). In many instances, the overexpression of activated RAP1 failed to activate ERK (for example, see Price et al. (2004)). Similarly, activation of endogenous RAP1 and RAP2 in murine B cell lines had no effect on ERK activity (Christian et al. 2003). The effects of RAP1GAP overexpression on ERK activity are also variable. Stable overexpression of RAP1GAP impaired ERK activity in squamous cell carcinoma cell lines (Zhang et al. 2006b), but not in pancreatic carcinoma cell lines (Zhang et al. 2006a). We now show that integrin activation, as evidenced by tyrosine phosphorylation of FAK and paxillin, is inhibited by RAP1GAP in PTC cell lines. RAP1GAP impaired phosphorylation of FAK and paxillin at sites phosphorylated by SRC. Unlike FAK and paxillin where phosphorylation was induced by plating, SRC phosphorylation was increased in suspended cells and decreased upon plating. Similar results have been reported in other cell types (Loza-Coll et al. 2005, Connelly et al. 2010). Intriguingly, RAP1GAP impaired SRC activity in suspended PTC cells. SRC inhibitors impaired cell spreading and migration, suggesting that at least some of the effects of RAP1GAP in thyroid cancer cells could be mediated through SRC inhibition. RAP1GAP did not impair SRC activity in KTC-1 cells. Unlike BCPAP and TPC-1 cells, KTC-1 cells were shown to be insensitive to SRC-mediated inhibition of growth, suggesting that the alterations in SRC signaling may have occurred in these cells (Schweppe et al. 2009). Although RAP1GAP impaired the spreading and motility of ATC cell lines, it did not consistently inhibit SRC, FAK, or paxillin phosphorylation in these cells. This implies that ATC cells have evolved to exploit signaling mechanisms different from those used in PTC cells.

Whether RAP1GAP directly impairs SRC activity or whether Src activity is decreased as a consequence of impaired spreading is unclear. FAK autophosphorylation was only modestly increased upon plating due to the absence of serum in these experiments. Under these conditions, overexpression of RAP1GAP partially decreased FAK phosphorylation. On the other hand, RAP1GAP decreased SRC activity in suspended cells in the absence of adhesion. Although the mechanistic details require further investigation, the notion that RAPIGAP expression impinges upon SRC/FAK signaling is of significant interest, given the pivotal role played by SRC/FAK complexes in tumor progression. There are examples of cross talk between RAP1GAP and FAK/SRC. Stable expression of RAP1GAP in pancreatic cancer, colon cancer, and melanoma cell lines impaired the formation of focal adhesions (Zhang et al. 2006a, Vuchak et al. 2009, Zheng et al. 2009). Overexpression of RAP1GAPII in A20 B-cell lymphoma cells impaired the recruitment of activated FAK and paxillin to the cell membrane (Lin et al. 2010). Perhaps most interestingly, silencing RAPIGAP increased SRC activity in human colon cancer cells (Tsygankova et al. 2010). Moreover, RAP1GAP-depleted colon carcinoma cells exhibited weakened cell/cell adhesion and enhanced spreading on collagen (Tsygankova et al. 2010), effects remarkably similar to those induced by SRC (Avizienyte \& Frame 2005).

SRC activity is increased in human thyroid cancer cell lines (Schweppe et al. 2009), in a mouse model of follicular thyroid cancer (Lu et al. 2010) and was required for spreading in TPC-1 cells (Caccia et al. 2010). The ability of RAP1GAP to impair SRC activity, cell spreading, and migration implies a role for RAP in the regulation of these events in thyroid cancer cells. This remains to be proven, as silencing the expression of RAP2 alone or in concert with RAP1 had no detectable effect on these parameters. This may be due to the fact that gene silencing was incomplete. Interestingly, the expression of constitutively active RAP2B impaired tyrosine phosphorylation of FAK and paxillin. This result implies that the cycling of RAP2 activity is important for reorganization of the actin cytoskeleton. It is also conceivable that RAP1GAP elicits RAP-independent effects that remain to be discovered. Further studies of the linkage between RAP1GAP, RAP2, and SRC may provide unique insight into the alterations in thyroid tumors that enhance dissemination and metastasis. 


\section{Declaration of interest}

The authors declare that there is no conflict of interest that could be perceived as prejudicing the impartiality of the research reported.

\section{Funding}

This work was supported by public health service grant CA127986 awarded to J L Meinkoth.

\section{Acknowledgements}

We thank Oxana M Tsygankova and Lisa A Vuchak for their helpful suggestion with experimental design.

\section{References}

Avizienyte E \& Frame MC 2005 Src and FAK signalling controls adhesion fate and the epithelial-to-mesenchymal transition. Current Opinion in Cell Biology 17 542-547. (doi:10.1016/j.ceb.2005.08.007)

Banerjee R, Mani RS, Russo N, Scanlon CS, Tsodikov A, Jing X, Cao Q, Palanisamy N, Metwally T, Inglehart RC et al. 2011 The tumor suppressor gene rap1GAP is silenced by miR-101-mediated EZH2 overexpression in invasive squamous cell carcinoma. Oncogene $\mathbf{3 0}$ 4339-4349. (doi:10.1038/onc.2011.141)

Bivona TG, Wiener HH, Ahearn IM, Silletti J, Chiu VK \& Philips MR 2004 Rap1 up-regulation and activation on plasma membrane regulates $\mathrm{T}$ cell adhesion. Journal of Cell Biology 164 461-470. (doi:10.1083/jcb.200311093)

Bos JL 2005 Linking Rap to cell adhesion. Current Opinion in Cell Biology 17 123-128. (doi:10.1016/j.ceb.2005. 02.009)

Caccia D, Micciche F, Cassinelli G, Mondellini P, Casalini P \& Bongarzone I 2010 Dasatinib reduces FAK phosphorylation increasing the effects of RPI-1 inhibition in a RET/PTC1-expressing cell line. Molecular Cancer 9 278. (doi:10.1186/1476-4598-9-278)

Carlomagno F \& Santoro M 2011 Thyroid cancer in 2010: a roadmap for targeted therapies. Nature Reviews. Endocrinology 7 65-67. (doi:10.1038/nrendo.2010.232)

Chevillard S, Ugolin N, Vielh P, Ory K, Levalois C, Elliott D, Clayman GL \& El-Naggar AK 2004 Gene expression profiling of differentiated thyroid neoplasms: diagnostic and clinical implications. Clinical Cancer Research: an Official Journal of the American Association for Cancer Research 10 6586-6597. (doi:10.1158/1078-0432.CCR04-0053)

Christian SL, Lee RL, McLeod SJ, Burgess AE, Li AH, Dang-Lawson M, Lin KB \& Gold MR 2003 Activation of the Rap GTPases in B lymphocytes modulates B cell antigen receptor-induced activation of Akt but has no effect on MAPK activation. Journal of Biological Chemistry 278 41756-41767. (doi:10.1074/jbc. M303180200)
Connelly SF, Isley BA, Baker CH, Gallick GE \& Summy JM 2010 Loss of tyrosine phosphatase-dependent inhibition promotes activation of tyrosine kinase c-Src in detached pancreatic cells. Molecular Carcinogenesis 49 1007-1021. (doi:10.1002/mc.20684)

Dahlman T, Lammerts E, Wik M, Bergstrom D, Grimelius L, Westermark K, Rubin K \& Heldin NE 2000 Fibrosis in undifferentiated (anaplastic) thyroid carcinomas: evidence for a dual action of tumour cells in collagen type I synthesis. Journal of Pathology 191 376-386. (doi:10.1002/1096-9896(2000)9999:9999<::AIDPATH643 > 3.0.CO;2-W)

Dong X, Korch C \& Meinkoth JL 2011 Histone deacetylase inhibitors upregulate Rap1GAP and inhibit Rap activity in thyroid tumor cells. Endocrine-Related Cancer 18 301-310. (doi:10.1530/ERC-10-0320)

Freeman SA, McLeod SJ, Dukowski J, Austin P, Lee CC, Millen-Martin B, Kubes P, McCafferty DM, Gold MR \& Roskelley CD 2010 Preventing the activation or cycling of the Rap1 GTPase alters adhesion and cytoskeletal dynamics and blocks metastatic melanoma cell extravasation into the lungs. Cancer Research 70 4590-4601. (doi:10.1158/0008-5472.CAN-09-3414)

Gloerich M \& Bos JL 2011 Regulating Rap small G-proteins in time and space. Trends in Cell Biology 21 615-623. (doi:10.1016/j.tcb.2011.07.001)

Janoueix-Lerosey I, Fontenay M, Tobelem G, Tavitian A, Polakis P \& de Gunzburg J 1994 Phosphorylation of Rap1GAP during the cell cycle. Biochemical and Biophysical Research Communications 202 967-975. (doi:10.1006/bbrc.1994.2024)

Knauf JA \& Fagin JA 2009 Role of MAPK pathway oncoproteins in thyroid cancer pathogenesis and as drug targets. Current Opinion in Cell Biology 21 296-303. (doi:10.1016/j.ceb.2009.01.013)

Lin KB, Tan P, Freeman SA, Lam M, McNagny KM \& Gold MR 2010 The Rap GTPases regulate the migration, invasiveness and in vivo dissemination of B-cell lymphomas. Oncogene 29 608-615. (doi:10.1038/onc.2009.345)

Loza-Coll MA, Perera S, Shi W \& Filmus J 2005 A transient increase in the activity of Src-family kinases induced by cell detachment delays anoikis of intestinal epithelial cells. Oncogene 24 1727-1737. (doi:10.1038/sj.onc. 1208379)

Lu C, Zhao L, Ying H, Willingham MC \& Cheng SY 2010 Growth activation alone is not sufficient to cause metastatic thyroid cancer in a mouse model of follicular thyroid carcinoma. Endocrinology 151 1929-1939. (doi:10.1210/en.2009-1017)

Mitra RS, Goto M, Lee JS, Maldonado D, Taylor JM, Pan Q, Carey TE, Bradford CR, Prince ME, Cordell KG et al. 2008 Rap1GAP promotes invasion via induction of matrix metalloproteinase 9 secretion, which is associated with poor survival in low N-stage squamous cell carcinoma. Cancer Research 68 3959-3969. (doi:10.1158/00085472.CAN-07-2755) 
Nellore A, Paziana K, Ma C, Tsygankova OM, Wang Y, Puttaswamy K, Iqbal AU, Franks SR, Lv Y, Troxel AB et al. 2009 Loss of Rap1GAP in papillary thyroid cancer. Journal of Clinical Endocrinology and Metabolism 94 1026-1032. (doi:10.1210/jc.2008-1042)

Ohba Y, Mochizuki N, Matsuo K, Yamashita S, Nakaya M, Hashimoto Y, Hamaguchi M, Kurata T, Nagashima K \& Matsuda M 2000 Rap2 as a slowly responding molecular switch in the Rap1 signaling cascade. Molecular and Cellular Biology 20 6074-6083. (doi:10.1128/MCB.20. 16.6074-6083.2000)

Prabakaran I, Grau JR, Lewis R, Fraker DL \& Guvakova MA 2011 Rap2A is upregulated in invasive cells dissected from follicular thyroid cancer. Journal of Thyroid Research 2011 1-6. (doi:10.4061/2011/979840)

Price LS, Hajdo-Milasinovic A, Zhao J, Zwartkruis FJ, Collard JG \& Bos JL 2004 Rap1 regulates E-cadherinmediated cell-cell adhesion. Journal of Biological Chemistry 279 35127-35132. (doi:10.1074/jbc. M404917200)

Raaijmakers JH \& Bos JL 2009 Specificity in Ras and Rap signaling. Journal of Biological Chemistry 284 10995-10999. (doi:10.1074/jbc.R800061200)

Saji M \& Ringel MD 2010 The PI3K-Akt-mTOR pathway in initiation and progression of thyroid tumors. Molecular and Cellular Endocrinology 321 20-28. (doi:10.1016/ j.mce.2009.10.016)

Schweppe RE, Klopper JP, Korch C, Pugazhenthi U, Benezra M, Knauf JA, Fagin JA, Marlow L, Copland JA, Smallridge RC et al. 2008 DNA profiling analysis of 40 human thyroid cancer cell lines reveals crosscontamination resulting in cell line redundancy and misidentification. Journal of Clinical Endocrinology and Metabolism 93 4331-4341. (doi:10.1210/jc.2008-1102)

Schweppe RE, Kerege AA, French JD, Sharma V, Grzywa RL \& Haugen BR 2009 Inhibition of Src with AZD0530 reveals the Src-focal adhesion kinase complex as a novel therapeutic target in papillary and anaplastic thyroid cancer. Journal of Clinical Endocrinology and Metabolism 94 2199-2203. (doi:10.1210/jc.2008-2511)

Spilker C \& Kreutz MR 2010 RapGAPs in brain: multipurpose players in neuronal Rap signalling. European Journal of Neuroscience 32 1-9. (doi:10.1111/ j.1460-9568.2010.07273.x)

van Staveren WC, Beeckman S, Tomas G, Dom G, Hebrant A, Delys L, Vliem MJ, Tresallet C, Andry G, Franc B et al. 2012 Role of Epac and protein kinase A in thyrotropin-induced gene expression in primary thyrocytes. Experimental Cell Research 318 444-452. (doi:10.1016/ j.yexcr.2011.12.022)

Tsygankova OM, Feshchenko E, Klein PS \& Meinkoth JL 2004 Thyroid-stimulating hormone/cAMP and glycogen synthase kinase $3\{\beta\}$ elicit opposing effects on Rap1GAP stability. Journal of Biological Chemistry 279 5501-5507. (doi:10.1074/jbc.M305824200)

Tsygankova OM, Prendergast GV, Puttaswamy K, Wang Y, Feldman MD, Wang H, Brose MS \& Meinkoth JL 2007 Downregulation of Rap1GAP contributes to Ras transformation. Molecular and Cellular Biology 27 6647-6658. (doi:10.1128/MCB.00155-07)

Tsygankova OM, Ma C, Tang W, Korch C, Feldman MD, Lv Y, Brose MS \& Meinkoth JL 2010 Downregulation of Rap1GAP in human tumor cells alters cell/matrix and cell/cell adhesion. Molecular and Cellular Biology 30 3262-3274. (doi:10.1128/MCB.01345-09)

Viglietto G, Amodio N, Malanga D, Scrima M \& De Marco C 2011 Contribution of PKB/AKT signaling to thyroid cancer. Frontiers in Bioscience: a Journal and Virtual Library 16 1461-1487. (doi:10.2741/3799)

Vuchak LA, Tsygankova OM, Prendergast GV \& Meinkoth JL 2009 Protein kinase A and B-Raf mediate extracellular signal-regulated kinase activation by thyrotropin. Molecular Pharmacology 76 1123-1129. (doi:10.1124/ mol.109.060129)

Zhang L, Chenwei L, Mahmood R, van Golen K, Greenson J, Li G, D'Silva NJ, Li X, Burant CF, Logsdon CD et al. $2006 a$ Identification of a putative tumor suppressor gene Rap1GAP in pancreatic cancer. Cancer Research 66 898-906. (doi:10.1158/0008-5472. CAN-05-3025)

Zhang Z, Mitra RS, Henson BS, Datta NS, McCauley LK, Kumar P, Lee JS, Carey TE \& D'Silva NJ 2006 $b$ Rap1GAP inhibits tumor growth in oropharyngeal squamous cell carcinoma. American Journal of Pathology 168 585-596. (doi:10.2353/ajpath.2006. 050132)

Zheng H, Gao L, Feng Y, Yuan L, Zhao H \& Cornelius LA 2009 Down-regulation of Rap1GAP via promoter hypermethylation promotes melanoma cell proliferation, survival, and migration. Cancer Research 69 449-457. (doi:10.1158/0008-5472.CAN-08-2399)

Zuo H, Gandhi M, Edreira MM, Hochbaum D, Nimgaonkar VL, Zhang P, Dipaola J, Evdokimova V, Altschuler DL \& Nikiforov YE 2010 Downregulation of Rap1GAP through epigenetic silencing and loss of heterozygosity promotes invasion and progression of thyroid tumors. Cancer Research 70 1389-1397. (doi:10.1158/0008-5472. CAN-09-2812)

Received in final form 7 June 2012 Accepted 13 June 2012 Made available online as an Accepted Preprint 13 June 2012 